\title{
Effects of Domain Size and Numerical Resolution on the Simulation of Shallow Cumulus Convection
}

\author{
D. Stevens
}

This article was submitted to American Meteorological Society, $11^{\text {th }}$ Conference on Cloud Physics, Ogden, UT, June 3-7, 2002

U.S. Department of Energy

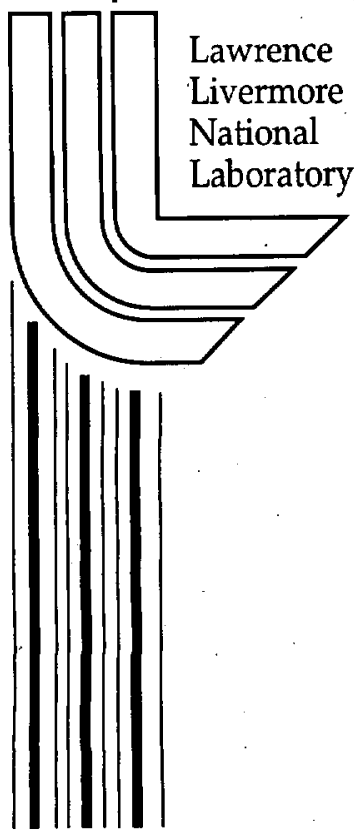

March 26, 2002 


\section{DISCLAIMER}

This document was prepared as an account of work sponsored by an agency of the United States Government. Neither the United States Government nor the University of California nor any of their employees, makes any warranty, express or implied, or assumes any legal liability or responsibility for the accuracy, completeness, or usefulness of any information, apparatus, product, or process disclosed, or represents that its use would not infringe privately owned rights. Reference herein to any specific commercial product, process, or service by trade name, trademark, manufacturer, or otherwise, does not necessarily constitute or imply its endorsement, recommendation, or favoring by the United States Government or the University of California. The views and opinions of authors expressed herein do not necessarily state or reflect those of the United States Government or the University of California, and shall not be used for advertising or product endorsement purposes.

This is a preprint of a paper intended for publication in a journal or proceedings. Since changes may be made before publication, this preprint is made available with the understanding that it will not be cited or reproduced without the permission of the author.

This report has been reproduced directly from the best available copy.

Available electronically at http://www.doe.gov/bridge

Available for a processing fee to U.S. Department of Energy and its contractors in paper from

U.S. Department of Energy Office of Scientific and Technical Information

P.O. Box 62

Oak Ridge, TN 37831-0062

Telephone: (865) 576-8401

Facsimile: (865) 576-5728

E-mail: reports@adonis.osti.gov

Available for the sale to the public from

U.S. Department of Commerce

National Technical Information Service

5285 Port Royal Road

Springfield, VA 22161

Telephone: (800) 553-6847

Facsimile: (703) 605-6900

E-mail: orders@ntis.fedworld.gov

Online ordering: http://www.ntis.gov/ordering.htm

OR

Lawrence Livermore National Laboratory

Technical Information Department's Digital Library

http://www.llnl.gov/tid/Library.html 


\title{
7.2 EFFECTS OF DOMAIN SIZE AND NUMERICAL RESOLUTION ON THE SIMULATION OF SHALLOW CUMULUS CONVECTION
}

\author{
David Stevens \\ Lawrence Livermore National Laboratory \\ Center for Applied Scientific Computing \\ 7000 East Ave., Livermore CA 94550
}

\section{Introduction}

This talk presents three-dimensional numerical simulations of oceanic trade cumulus clouds underlying stratocumulus clouds. It is based on a Global Energy and Water Experiment (GEWEX) Cloud System Study (GCSS) model intercomparison that is loosely based on observed conditions during the Atlantic Trade Cumulus Experiment (ATEX). It is motivated by the importance of this cloud type to global cloud radiative forcing, and its role as a feeder system for deep convection in the tropics. This study focuses on the sensitivity of the modeled cloud field to the domain size and the grid spacing by studying two sequences of simulations with different domain widths of 6.4 and 20.2 kilometers. Each sequence contains simulations where the horizontal mesh spacing ranged from 10 to 80 meters and the vertical from 5 to $40 \mathrm{~m}$. The combination of large domain size and small grid resolution (up to 2.5 billion grid-cells) provides an unprecedented perspective on this type of convection. This is in contrast to Prior LES simulations which have often used domains a few kilometers wide. The larger domain size considered here is comparable to the grid resolution of a typical current mesoscale model (a similar resolution will soon be achieved in some global weather forecast models), and can better represent the potential horizontal variability achievable within a mesoscale grid cell.

Oceanic trade cumulus convection is an intermediate regime in the Hadley cell, which at its poleward end originates as a stratocumulus-capped boundary layer under strong large-scale subsidence. The subtropical stratocumulus to trade cumulus transition (STCT) is observed to be gradual, starting with the formation of shallow cumuli feeding into the stratocumulus clouds, followed by the breakup of the overlying stratocumulus layer (Wyant et al. 1997). The STCT is a challenging parameterization problem for general circulation models, due in part to an incomplete understanding of turbulent mixing processes in trade cumulus clouds. Intercomparisons of current general circulation models show that most models represent the geographical and temporal variation of this cloud type very poorly, generating large regional errors. (Houghton and Meira 1995). This and other studies have stimulated recent interest in the ability of large-eddy simulation (LES) models to accurately simulate the STCT.

The GCSS model intercomparison, focused on the regime of cumulus clouds rising into a patchy stratocumulus layer. Seven LES models were studied (including this one) through simulations which followed a strict specification of forcings, domain size and resolution. This intercomparison was conceived in part as a comparison to a prior GCSS study of pure trade cumulus convection (Siebesma et al: 2001), based on large-scale conditions observed during part of BOMEX (the Barbados Oceanographic and Meteorological EXperiment). In the BOMEX case, no stratocumulus clouds were observed or simulated by LES. The boundary layer was forced by a fixed profile of radiative cooling; cloud-radiation feedback was considered, but it had only minor effects. The participating LES models all produced very similar statistics of cloud cover and cumulus mass flux as functions of height. The BOMEX case suggested that LES models could robustly simulate the statistics of trade cumuli at computationally reasonable grid resolutions.

In contrast the ATEX intercomparison included a simple Beer's Law feedback of cloud liquid water on radiation in addition to the specified clear-air radiative cooling. This feedback, coupled with a stronger and thinner trade inversion, greatly amplified numerical differences due to differences in the transport algorithms used. This led to large inter-model variations in the predicted stratocumulus cloud fraction and inversion deepening rate. B. Stevens et al. (2001) 

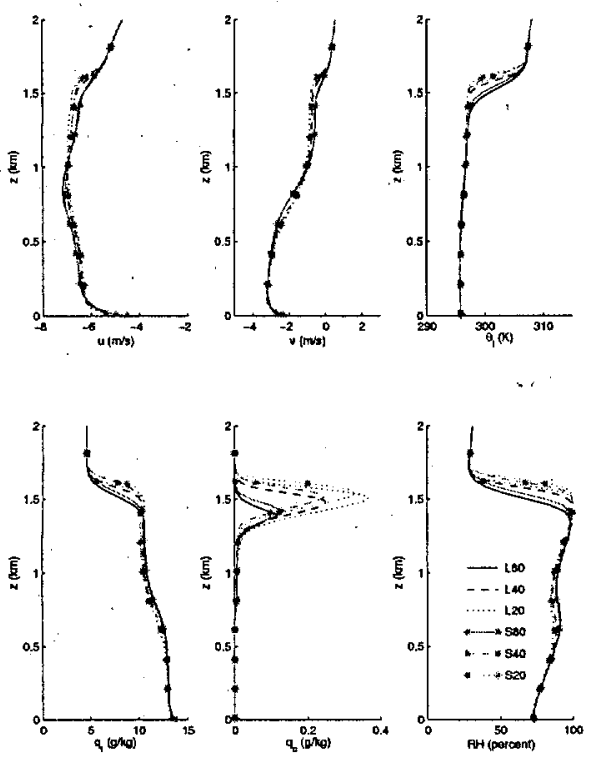

Figure 1: Horizontally averaged profiles. These profiles are three hour averages centered on the sixth hour of simulation.

presented two sensitivity studies where one of the participating models doubled the vertical resolution and another model used $20 \mathrm{~m}$ resolution in all directions. The stratocumulus cloud fraction was greatly increased at the higher resolutions, in contrast to the BOMEX case.

\section{2 the modeling study}

The model used in this study integrates a modified form of the anelastic equations of Ogura and Phillips (1962) and is described by D. Stevens and Bretherton (1997). Each sequence includes three simulations with horizontal grid-spacings 80,40 and $20 \mathrm{~m}$, and vertical grid-spacing equal to half of the horizontal grid spacing. Simulation names are denoted by $(S, L)$ for the domain size, small and large respectively, followed by a number indicating the horizontal resolution used in meters. Each simulation was integrated for a period of 8 simulated hours for purposes of establishing statistically steady profiles. For the large domain sequence, an additional ultra-high resolution simulation, L10, was performed with $10 \mathrm{~m}$ horizon$\mathrm{tal} / 5 \mathrm{~m}$ vertical resolution. It was spawned from the end of the seventh hour of the 20 meter horizontal resolution simulation and only computed for fifteen minutes of simulated time. Although not long enough to generate statistically stable scalar statistics

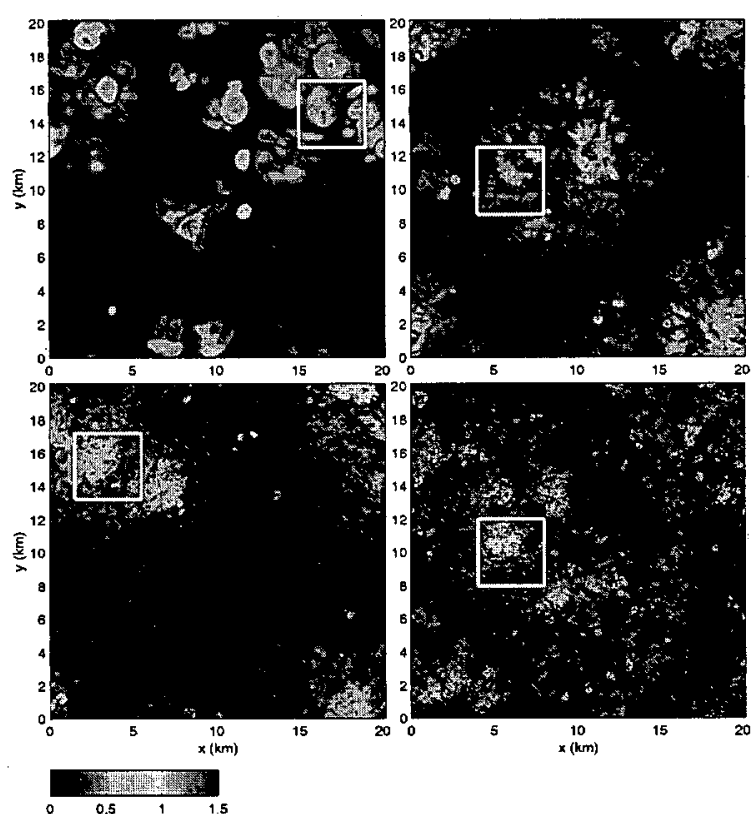

Figure 2: Horizontal cross sections of cloud water, $q_{c}\left(\mathrm{~g} \mathrm{~kg}^{-1}\right)$, at an altitude of $1400 \mathrm{~m}$ for the entire domain, taken after 7 hours of simulation. The simulations are L80 (upper left), L40(upper right), L20(lower left) and L10(lower right). White boxes indicate regions where the higher resolution cross sections of Figure 3 are taken. The cross section from L10 was taken at 7 hours, 15 minutes.

and mean profiles, this simulation was long enough to demonstrate changes in convective clouds and the vertical velocity spectrum. This simulation is the most computationally intensive simulation of cloudtopped boundary layer turbulence to date that we are aware of, using 1008 processors and 1.3 terabytes of memory.

Vertical profiles of the horizontal-mean velocities and thermodynamic quantities are shown in Figure 1 for all simulations, except L10, as three hour averages over hours 5 through 7 of simulation. Over most of the boundary layer, the profiles are qualitatively similar between simulations. There is a relatively wellmixed subcloud layer extending up to $600 \mathrm{~m}$, just below the cumulus cloud base. Above, there is a cumulus cloud layer in which the horizontal mean relative humidities are 90-100 percent. The strongest vertical gradients within the cumulus layer are in the transition layer just above cloud base. An $8 \mathrm{~K}$ trade inversion separates the boundary layer from the drier free troposphere above. The flow is northeasterly in the boundary layer, transitioning to easterly in the cloudy layer and above. Near the trade inversion, 
the differences between simulations are much more striking. At high resolution, there is a dramatic increase in condensed water, $q_{c}$, corresponding to the formation of a stratiform cloud layer just below the trade inversion. The inversion has risen further and is also much sharper, although this is smeared out in Figure 1 by the time-averaging.

Figure 2 shows horizontal cross-sections of $q_{c}$ for simulations L10 to L80 at a height of 1400 meters, just below the altitude of maximum stratocumulus cloud cover. All four cross-sections have 'mesoscale' cloud free regions that are bigger than the entire domain of the smaller domain sequence of S20 to S80. As the resolution is increased, the visual appearance of the cloud field changes substantially, and in particular many more small cloud elements appear. Figure 3 zooms in on some typical convective elements indicated by the white rectangles of Figure 2. The amount of $q_{c}$ variation on lengthscales comparable to the grid scale is striking. In the highest resolution run, cloud filaments of high liquid water content are closely intermingled with unsaturated dry air, reflecting the impact of small-scale mixing and entrainment.

The impact of resolution on the vertical structure of typical large convective elements is shown in Figure 4. The low resolution simulation $\mathrm{L} 80$ resolves only the main cumulus updraft, the maximum $q_{c}$ is well below the cloud top due to diffusion and there is no evidence of resolved-scale overturning at the trade inversion. L40 shows some eddy structure within an individual cumulus updraft, and maximum liquid water contents at cloud top. In L20, parts of the cloud top are overturned, indicating resolved-scale entrainment through the inversion. L10 is characterized by an even more filamentary cloud, with well-resolved turrets reflecting the influence of penetrative and lateral entrainment. From these figures, it appears that the resolution of $\mathrm{L} 10$ is required to produce a convincing simulation of mixing processes and liquid water statistics in individual small cumulus clouds.

The total flux profiles of $v$ (crosswind momentum), $\theta_{l}$ (liquid water potential temperature) and $q_{t}$ (total water mixing ratio) are shown in Figure 5. These profiles are shown in Stevens, Ackermann, and Bretherton (2002) to be the result of differences between simulations in cloud radiative forcing and entrainment. More, thicker stratocumulus cloud and increased radiative forcing drive stronger entrainment fluxes of momentum, heat and moisture. The individual convective elements in the lower and middle parts of the cloudy layer have transport properties that are
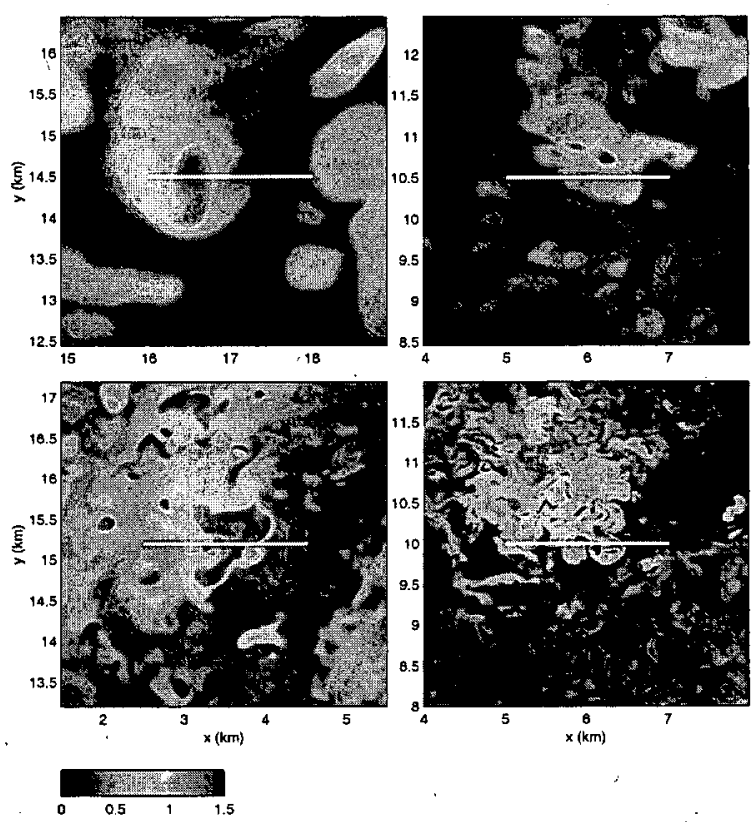

Figure 3: Horizontal cross sections of cloud water, $q_{c}\left(\mathrm{~g} \mathrm{~kg}^{-1}\right)$, over the $4 \times 4 \mathrm{~km}$ highlighted boxes in Figure 2. The white lines indicate where the vertical cross sections of Figure 4 are taken.
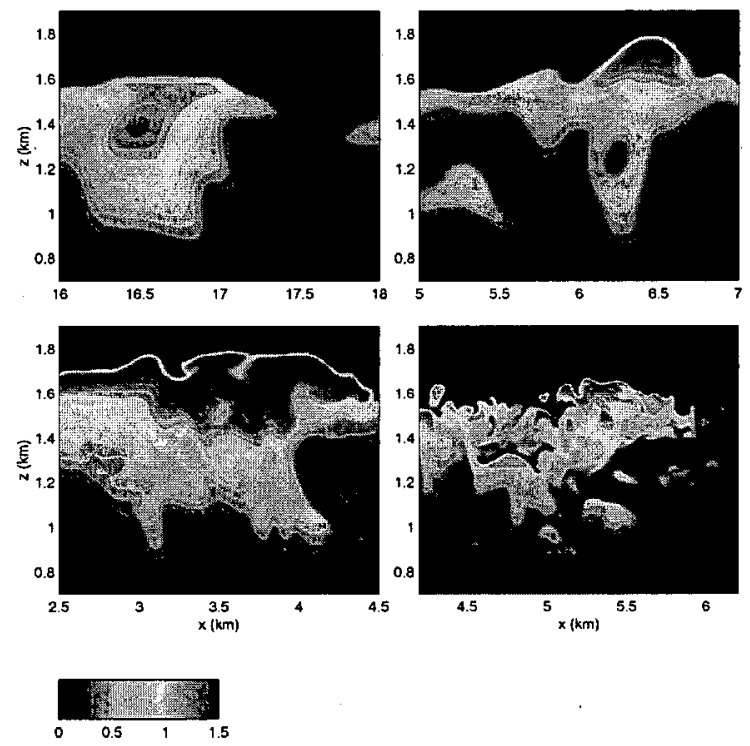

Figure 4: Vertical cross sections of cloud water corresponding to the white lines in Figure 3. 

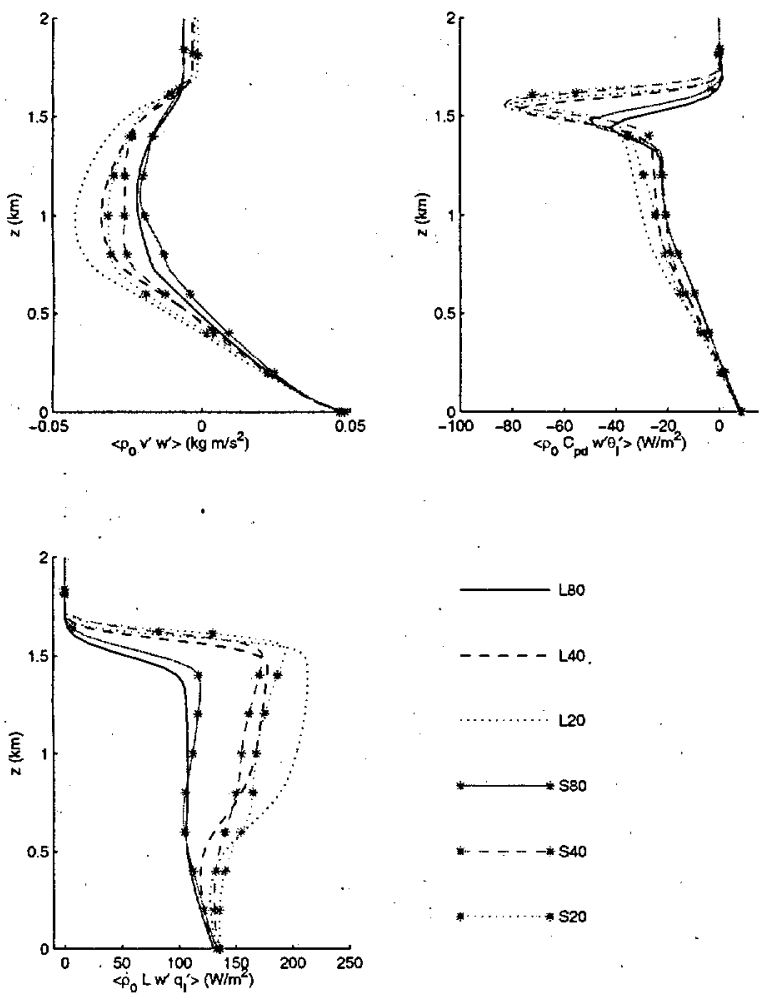

Figure 5: Total vertical fluxes of crosswind momentum (top left), $\theta_{l}$ (top right), and $q_{t}$ (bottom left).

fairly insensitive to the resolution and domain size. However, stronger radiative destabilization near the trade inversion supports more active convection and stronger fluxes in the finer resolution simulations.

\section{Conclusions}

This study presents results from two sequences of simulations where the resolution is increased while the aspect ratio of horizontal to vertical mesh spacings is fixed at $2 / 1$. One sequence uses a conventional domain width of $6 \mathrm{~km}$; the other uses a 'large' domain width of $20 \mathrm{~km}$ more capable of simulating mesoscale variability.

New scales of motion appear with each doubling of resolution. The coarsest simulation models the convection as broad homogeneous updrafts that entrain and detrain in a diffusion-like process, whereas the finest-grid simulation resolves the eddies responsible for lateral entrainment and even penetrative entrainment through the sharp, strong trade inversion.
Changes in resolution and domain size feed back on the bulk characteristics of the boundary layer through the strong positive feedback of cloud on longwave radiative cooling in this case study. With a finer grid spacing, stratocumulus can form under the inversion without excessive erosion by numerical diffusion. This promotes more cloud cover, more radiative cooling and stronger turbulence at the inversion base. The increase in domain size was often complementary to the changes in resolution.

The primary goal of this study is to investigate the turbulent dynamics that one can only resolve at these very high resolutions and large domain sizes. In pursuit of this goal, a number of simplifications have been made to the treatment of microphysical and radiative processes. An area of future work is to combine the domain size and resolution used in this study with a more comprehensive treatment of these processes.

\section{Bibliography}

Houghton, J. and G. Meira, 1995: SAR, the Second Assessment Report of the intergovernmental panel on Climate Change, Cambridge University Press.

Siebesma, A. P., and J. W. M. Cjuipers, 1995: Evaluation of parametric assumptions for shallow cumulus convection. J. Atmos. Sci., 52, 650-666.

Stevens, B, A. S. Ackermann, B. A. Albrecht, A. R. Brown, A. Chlond, J. Cuxart, P. G. Duynkerke, D. C. Lewellen, M. K. MacVean, E. Sanchez, A. P. Siebesma, and D. E. Stevens, 2001: Simulations of trade-wind cumuli under a strong inversion $J$. Atmos. Sci., 58, 1870-1891.

Stevens, D. E. and C. S. Bretherton, 1997: A forwardin-time advection scheme and adaptive multilevel flow solver for nearly incompressible atmospheric flow. J. Comput. Phys., 129, 284-295.

Stevens, D. E. A. S. Ackermann, and C. S. Bretherton, 2002: Effects of domain size and numerical resolution on the simulation of shallow cumulus convection. J. Atmos. Sci., Accepted subject to revision February 2002.

Wyant, M. C., C. S. Bretherton, H. A. Rand and D. E. Stevens: Numerical Simulations and a Conceptual Model of the Stratocumulus to Trade Cumulus Transition. J. Atmos. Sci., 54, 168-192, 1996. 